\title{
Mesenchymal stem cell-based therapies in regenerative medicine: applications in rheumatology
}

\author{
Marie Maumu11,2, David Guérit1,2, Karine Toupet ${ }^{1,2}$, Christian Jorgensen ${ }^{1,2,3}$ and Danièle Noël*1,2,4
}

\begin{abstract}
Growing knowledge on the biology of mesenchymal stem cells (MSCs) has provided new insights into their potential clinical applications, particularly for rheumatologic disorders. Historically, their potential to differentiate into cells of the bone and cartilage lineages has led to a variety of experimental strategies to investigate whether MSCs can be used for tissue engineering approaches. Beyond this potential, MSCs also display immunosuppressive properties, which have prompted research on their capacity to suppress local inflammation and tissue damage in a variety of inflammatory autoimmune diseases and, in particular, in rheumatoid arthritis. Currently, an emerging field of research comes from the possibility that these cells, through their trophic/regenerative potential, may also influence the course of chronic degenerative disorders and prevent cartilage degradation in osteoarthritis. This review focuses on these advances, specifically on the biological properties of MSCs, including their immunoregulatory characteristics, differentiation capacity and trophic potential, as well as the relevance of MSC-based therapies for rheumatic diseases.
\end{abstract}

\section{Introduction}

For several years, mesenchymal stem cells (MSCs; also called mesenchymal stromal cells) have been largely studied and used as a new therapeutic tool for a number of clinical applications, in particular for the treatment of rheumatologic disorders. MSCs indeed have therapeutic potential for bone and joint diseases due to their multipotent differentiation abilities and the secretion of a

*Correspondence: daniele.noel@inserm.fr

${ }^{4}$ Inserm U844, CHU Saint Eloi, Bâtiment INM, 80 avenue Augustin Fliche,

Montpellier, F-34295 France

Full list of author information is available at the end of the article variety of cytokines and growth factors that confer on them anti-fibrotic, anti-apoptotic, pro-angiogenic and immunosuppressive properties. They are currently being tested in several clinical trials for such diverse applications as osteoarthritis, osteogenesis imperfecta, articular cartilage defects, osteonecrosis and bone fracture. Moreover, good manufacturing practices for the production of clinical-grade MSCs at high expansion rates without transformation are now well established [1]. Here, we review the present knowledge on the mechanisms underlying the therapeutic properties of MSCs and their applications in animal models and clinics in the fields of bone and cartilage repair, chronic inflammatory or degenerative disorders, as well as genetic diseases.

\section{Definition of mesenchymal stem cells: location and characterization}

MSCs were first identified in the bone marrow (BM) [2] but are now described to reside in connective tissues and notably in adipose tissue (AT) [3], placenta [4], umbilical cord [5], dental pulp [6], tendon [7], trabecular bone [8] and synovium [9]. It has also been suggested that MSCs could reside in virtually all post-natal organs and tissues [10]. BM and AT are, however, the two main sources of MSCs for cell therapy due to high expansion potential and reproducible isolation procedures. Historically, the first characterized MSCs derived from BM remain the most intensively studied and are still the reference. ATderived MSCs (ASCs) are easier to isolate in high numbers. Nevertheless, while they display characteristics similar to BM-MSCs, their transcriptomic and proteomic profiles show specificities particular to the tissue origin [11]. MSCs have also been described to reside in a perivascular location and to express markers specific for pericytes [12,13]. However, in AT, ASCs are mainly located in the stroma around the adipocytes and only few of them have a perivascular location. Importantly, in the tissue, none or very few ASCs express pericyte markers, even those that are located around the vessels [14].

MSCs are defined according to three criteria proposed by the International Society for Cellular Therapy [15]. 
First, MSCs are characterized as a heterogeneous cell population that is isolated by its property of adherence to plastic. In culture, MSCs are able to develop as fibroblast colony forming-units. Second, MSCs are distinguished by their phenotype: MSCs express the cell surface markers CD73, CD90 and CD105 and are negative for CD11b, CD14, CD34, CD45 and human leukocyte antigen (HLA)-DR. More recently, the CD271 marker was used to isolate highly enriched BM-MSC populations [16]. Whereas BM-MSCs are negative for the CD34 marker, native ASCs can be isolated according to CD34 expression, although this rapidly disappears with cell proliferation in vitro $[14,17]$. The third criterion to define MSCs, based on a functional standard, is their capacity to differentiate into at least three mesenchymal lineages, namely bone, fat and cartilage.

\section{Functional properties of mesenchymal stem cells}

Differentiation capacity and paracrine signaling are both properties relevant for therapeutic applications of MSCs. MSC differentiation contributes by regenerating damaged tissue, whereas MSC paracrine signaling regulates the cellular response to injury.

\section{Differentiation properties}

MSCs are an attractive source of cells for bone and cartilage engineering because of their osteogenic and chondrogenic potential. Their differentiation capacity is generally shown in vitro using specific culture conditions but also in vivo in different animal models [18]. Besides this trilineage potential, MSCs can also differentiate into myocytes [19], tendinocytes [20], cardiomyocytes [21], neuronal cells with neuron-like functions [22,23] and other cell types. The differentiation potential is dependent on environmental factors, such as growth factors, but also physical parameters, such as oxygen tension, shear and compressive forces, and elasticity of the extracellular three-dimensional environment.

\section{Paracrine properties}

MSCs release various soluble factors that influence the microenvironment by either modulating the host immune response or stimulating resident cells.

The immunomodulatory properties of MSCs, characterized by the capacity to inhibit the proliferation and function of all immune cells, have been largely described both in vitro and in vivo (reviewed in [24]). Immunomodulation requires the preliminary activation of MSCs by immune cells through the secretion of the proinflammatory cytokine IFN- $\gamma$, together with TNF- $\alpha$, IL- $1 \alpha$ or IL- $1 \beta[25,26]$. The induction of MSC immunomodulation is principally mediated by soluble mediators. Among these, indoleamine 2,3-dioxygenase has been shown to be a major player in human MSCs but absent or poorly expressed in murine cells, while nitric oxide is expressed at low levels in human MSCs but at high levels in murine MSCs following IFN- $\gamma$ stimulation [26]. Transforming growth factor (TGF)- $\beta 1$, hepatocyte growth factor (HGF), heme oxygenase1, IL6, leukemia inhibitory factor, HLAG5, IL-10 and IL-1 receptor antagonist (IL-1RA) as well as prostaglandin E2 have been proposed as other mediators involved in MSCmediated immunomodulation (reviewed in [24]). MSCs suppress B- and T-cell proliferation and alter their function, inhibit the proliferation of activated natural killer cells, interfere with the generation of mature dendritic cells from monocytes or $\mathrm{CD}_{3} 4^{+}$progenitor cells, and induce an immature dendritic cell phenotype [27,28]. Finally, MSCs inhibit Th17 cell differentiation and induce fully differentiated Th17 cells to exert a T cell regulatory phenotype [29].

Although soluble mediators are the main actors in MSC immunosuppression, cell-cell interactions have been shown to be involved in this process. Recently, tolllike receptor (TLR) stimulation has been shown to modulate the action of MSCs on the immune system. Indeed, TLR4-primed MSCs, or MSC1, mostly elaborate pro-inflammatory mediators, while TLR3-primed MSCs, or MSC2, express mostly immunosuppressive ones [30].

The trophic properties of MSCs are related to the tissue regeneration process through bioactive factors. These factors may act directly, triggering intracellular mechanisms of injured cells, or indirectly, inducing secretion of functionally active mediators by neighboring cells. MSCs are capable of attenuating tissue injury, inhibiting fibrotic remodeling and apoptosis, promoting angiogenesis, stimulating stem cell recruitment and proliferation, and reducing oxidative stress. As an example, in a hamster heart failure model, intramuscularly injected MSCs, or even more importantly MSC-conditioned medium, significantly improve cardiac function. Improvement occurred via soluble mediators acting on proliferation and angiogenesis, resulting in higher numbers of myocytes and capillaries, and on apoptosis and fibrosis, which were significantly reduced [31]. The prominent factors identified in these processes were HGF and vascular endothelial growth factor (VEGF). The authors demonstrate the activation of the JAK-STAT3 axis in myocytes, which increases the expression of the target genes $H G F$ and $V E G F$ [32]. Activation of the STAT3 pathway is crucial since its inhibition by TLR4 activation inhibits MSCmediated cardioprotection [33]. Secretion of VEGF by MSCs also attenuates renal fibrosis through immune modulation and remodeling properties in different models of kidney injury $[34,35]$. The other mediators that are important actors during tissue remodeling and fibrosis formation are matrix metalloproteinases (MMPs) and tissue inhibitors of MMP (TIMPs). MSC-secreted 
TIMPs are capable of playing important roles both under physiological conditions in their niche and in pathological situations [36,37].

\section{Chemotactic properties}

Injured tissues express specific receptors or ligands that are believed to trigger the mobilization of MSCs into the circulation, facilitating trafficking, adhesion and infiltration of MSCs to the damaged or pathological tissues, in a mechanism similar to the recruitment of leukocytes to sites of inflammation. In the damaged tissues, MSCs are believed to secrete a broad spectrum of paracrine factors that participate in the regenerative microenvironment and regulate immune infiltration [38]. Administration of MSCs, either systemically or locally, has been reported to contribute to tissue repair, suggesting the need to enhance the pool of endogenous MSCs with exogenously administered MSCs for efficient repair. A better understanding of MSC trafficking and homing mechanisms should help in designing novel therapeutic options to compensate for a deficiency in the number or function of MSCs that may occur in injured tissues.

\section{Therapeutic applications of MSCs in rheumatology MSCs for bone and cartilage repair}

Interest in using MSCs for tissue engineering has been validated in numerous pre-clinical models and is under evaluation in clinics. At least 16 clinical trials are recruiting for the therapeutic application of MSCs for cartilage defects, osteoporosis, bone fracture, or osteonecrosis. For successful tissue engineering approaches, implantation of MSCs will require the use of growth and differentiation factors that will allow the induction of the specific differentiation pathways and the maintenance of the bone or chondrocyte phenotype together with an appropriate scaffold to provide a three-dimensional environment. Defining the optimal combination of stem cells, growth factors and scaffolds is thus essential to provide functional bone and cartilage.

Bone engineering strategies are warranted in cases of large bone defects or non-union fractures, which remain a serious problem as the associated loss of function considerably impairs the quality of life of affected patients. A vast variety of bone graft substitutes is already commercially available or under intense pre-clinical investigation to evaluate their appropriateness to serve as biomaterials for tissue engineering strategies (reviewed in [39]). Briefly, bone substitutes are assigned to the group of either inorganic (mostly calcium phosphate- or calcium sulphate-based materials, or bioactive glasses) or organic matrices (natural processed bone graft or synthetic polymers). Moreover, it has to be stressed that the success of bone graft substitutes needs a functional vascular network to obtain high quality osseous tissue.
Enhanced vascularisation is generally achieved by the provision of angiogenic growth factors that have been shown to increase bone healing [40]. To date, corticocancellous bone grafts remain the most frequently used way of reconstructing large bone segments. Despite promising reports on the potential of bone engineering, particularly for oral and maxillofacial surgeries, these innovative therapeutic strategies have so far been too sporadic, and with low numbers of patients, to give interpretable results. Further efforts are needed to state more precisely the indications in which tissue engineered constructs could replace conventional therapies and improve clinical outcome of patients.

After traumatic or pathological injury, the capacity of adult articular cartilage to regenerate is limited. The current proposed surgeries (microfracture, osteochondral auto- or allografts, or cell-based therapies using chondrocytes) may lead to fibrocartilage and not restore hyaline articular cartilage in the long term. Several kinds of combined scaffolds have been evaluated for cartilage engineering using MSCs (reviewed in [41]). More recently, micron-sized fibers, produced by the electrospinning technique, were shown to provide a structure and properties comparable to the cartilage extracellular matrix and to enhance chondrogenesis [42]. Efforts are being made to improve scaffolds by combining several biomaterials (poly(lactic-co-glycolic acid) sponge and fibrin gel) with an inducing factor (TGF- $\beta 1$ ) with satisfactory results [43]. Recently, our group has shown that MSC-coated pharmacologically active microcarriers releasing TGF- $\beta 3$ implanted in severe combined immunodeficiency (SCID) mice resulted in the formation of cartilage, suggesting that they could represent a promising injectable biomedical device for cartilage engineering [44]. An alternative way to avoid direct transplantation of MSCs for tissue engineering is to recruit endogenous progenitor cells. Indeed, the replacement of the proximal condyle in a rabbit by a TGF- $\beta 3$-infused bioscaffold resulted, 4 months later, in a scaffold fully covered with avascular hyaline cartilage in the articular surface. The scaffold was also integrated within the regenerated subchondral bone, suggesting that the regeneration was probably due to homing of endogenous cells [45]. Although much progress has been made in the manipulation of cells and constructs for cartilage engineering, the generation of functional repaired tissue remains to be optimized.

\section{MSCs for treatment of genetic diseases}

Recent advances in stem cell research have prompted the development of cell-based therapies to replace cells that are deficient in genetic diseases [46]. Osteogenesis imperfecta is a rare genetic disorder due to abnormal collagen type I production by osteoblasts, resulting in 
osteopenia, multiple fractures, severe bone deformities and considerably shortened stature. To replace defective osteoblasts, the infusion of allogeneic whole BM or isolated BM-MSCs producing normal collagen type I was evaluated in two studies [47,48]. Although linear growth rate, total body bone mineral content, and fracture rate improved in some patients, the relatively short-term follow-up prevented the authors from drawing firm conclusions about the efficacy of MSC therapy. In a subsequent study with infusions of labelled BM-MSCs, Horwitz and colleagues reported that engraftment was evident in one or more sites, including bone, skin, and marrow stroma, in five out of six patients. These five patients had an acceleration of growth velocity during the first 6 months after infusion [48]. Moreover, the transplantation of allogeneic foetal liver-derived MSCs in a foetus with severe osteogenesis imperfecta led to $0.3 \%$ of cell engraftment and differentiation of the donor cells into osteocytes until more than 9 months after transplant [49].

Hypophosphatasia, another metabolic bone disease, is a rare, heritable disease due to deficient activity of tissue nonspecific alkaline phosphatase, often causing death in the first year of life due to respiratory complications. In a young girl, transplantation of 5/6 HLA-matched T-celldepleted BM resulted in clinical and radiographic improvement without correction of the biochemical features of hypophosphatasia during the first 6 months [50]. However, skeletal demineralization occurred 13 months after transplantation and the decision was therefore taken to infuse BM cells that had been expanded ex vivo. Six months later, considerable, lasting clinical and radiographic improvement ensued, still without correction of her biochemical abnormalities. Despite the small number of studies, patients with metabolic bone diseases have benefited from allogeneic MSC therapy.

\section{MSCs for the treatment of inflammatory disorders}

Due to their immunosuppressive properties, MSCs may be of interest in the treatment of inflammatory disorders such as rheumatoid arthritis, which is the most prominent inflammatory rheumatic disease. To date, conflicting results have been reported using the collagen-induced arthritis (CIA) experimental mouse model. In several studies, the injection of MSCs derived from BM or AT in the CIA mouse model after the establishment of the disease improved the clinical score. These effects were associated with a decrease in Th1-driven inflammation and TNF- $\alpha$ or IFN- $\gamma$ serum levels as well as induction of a regulatory $\mathrm{T}$ cell phenotype [51,52]. More recently, our group has shown that IL-6-dependent prostaglandin E2 secretion by MSCs inhibits local inflammation in experimental arthritis [53]. However, this beneficial effect of MSCs in rheumatoid arthritis is still controversial since different studies have shown that the injection of the C3H10T1/2 MSC line, Flk-1(+) MSCs, or MSCs derived from DBA/1 mice did not exert a positive effect on CIA or even aggravate the symptoms [54,55]. This discrepancy in the effect of MSCs may be caused by the different sources of MSCs, but we have reported that altering the course of the disease depends on precise timing of MSC administration [53]. This therapeutic window is likely to be associated with the immune status of the mice since it has been recently reported that MSCs are polarized towards an inflammatory MSC1 or immunosuppressive MSC2 phenotype depending on the type of TLR activation [30].

\section{MSCs for treatment of chronic degenerative disorders}

Osteoarthritis is the most frequent rheumatic disease and is characterized by degeneration of articular cartilage, mainly due to changes in the activity of chondrocytes in favor of catabolic activity. However, recent data now suggest that osteoarthritis also involves other joint tissues, with alterations of the meniscus, sclerosis and edema in the underlying subchondral bone as well as intermittent inflammation of synovium. MSC-based therapy may act via two ways, either preventing cartilage degradation through the secretion of bioactive factors, or by differentiating into chondrocytes and contributing to cartilage repair. The different options to deliver MSCs to the osteoarthritis joint have been summarized recently [56]. Indeed, the co-culture of human MSCs with primary osteoarthritis chondrocytes allowed the differentiation of MSCs towards chondrocytes even in the absence of growth factors. This effect was dependant on cell-cell communication for secretion of morphogen by chondrocytes, suggesting that MSCs injected in a joint might differentiate into chondrocytes [57]. Secretion of bioactive mediators by MSCs may prevent loss of chondrocyte anabolic activity or stimulate progenitors present in the cartilage. As an example, the delivery of autologous MSCs to caprine joints subjected to total meniscectomy and resection of the anterior cruciate ligament resulted in regeneration of meniscal tissue and significant chondroprotection [58]. In an experimental rabbit model of osteoarthritis, transplantation of a hyaluronan-based scaffold seeded with BM-MSCs statistically improved the quality of the regenerated tissue compared to the animal control [59]. Loss of proteoglycans and osteophyte formation were less in the animals treated with MSCs. In humans, eight clinical trials are currently recruiting patients to test the efficacy of MSC injection for treatment of osteoarthritis. Indeed, a phase I/II trial is currently evaluating the effect of MSC injection with hyaluronan (in the form of Chondrogen ${ }^{\mathrm{TM}}$ ) to prevent subsequent $\mathrm{OA}$ in patients undergoing 
This article is part of a review series on Immunology and stem cells, edited by Christian Jorgensen. Other articles in the series can be found online at http://stemcellres.com/series/immunology

meniscectomy. The mechanisms of MSC-based therapy remain unknown, but it has been speculated that secreted biofactors might reduce fibrocartilage formation or decrease degradation by inhibiting proteinases. Moreover, although osteoarthritis is not considered an inflammatory disease, secretion of cytokines, namely IL- $1 \beta$ and TNF- $\alpha$, and immune responses may also be suppressed thanks to the immunomodulatory effects of MSCs. The various reports therefore argue for a therapeutic efficacy of MSCs in preventing or limiting osteoarthritis lesions in patients.

\section{Conclusion}

Stem cell therapies represent an innovative approach for the treatment of diseases for which currently available treatments are limited. Because MSCs could operate through many different mechanisms, MSC-based therapies are undergoing rapid development and have generated great expectations. Their therapeutic potential is currently being explored in a number of phase I/II trials, and three phase III trials have been concluded for the treatment of graft-versus-host-disease, Crohn's disease (Prochymal ${ }^{\oplus}$, Osiris Therapeutics) and perianal fistula (Ontaril ${ }^{\circ}$, Cellerix). While the data from numerous clinical trials are encouraging, future studies are obviously needed to confirm the phase I/II studies. They have nevertheless paved the way for the establishment of feasibility and administration protocols as well as the safety of the procedures. This should encourage initiating further clinical studies in non life-threatening pathologies such as rheumatic diseases.

\section{Abbreviations}

ASC, AT-derived MSC; AT, adipose tissue; BM, bone marrow; CIA, collageninduced arthritis; HGF, hepatocyte growth factor; HLA, human leukocyte antigen; IFN, interferon; IL, interleukin; MSC, mesenchymal stem cell; TGF, transforming growth factor; TLR, toll-like receptor; TNF, tumor necrosis factor; VEGF, vascular endothelial growth factor.

\section{Competing interests}

The authors declare that they have no competing interests.

\section{Acknowledgements}

This work in the laboratory Inserm U844 is supported by the Inserm Institute, the University of Montpellier I and a grant from the European Community (FP7-HEALTH-2009-Large-scale integrating project: 'Adipose derived stromal cells for osteoarthritis treatment').

\section{Author details}

IInserm, U844, Montpellier, F-34091 France. ${ }^{2}$ Université Montpellier 1, UFR de Médecine, Montpellier, F-34000 France. ${ }^{3}$ Service d'immuno-Rhumatologie, Hôpital Lapeyronie, Montpellier, F-34295 France. ${ }^{4}$ Inserm U844, CHU Saint Eloi, Bâtiment INM, 80 avenue Augustin Fliche, Montpellier, F-34295 France.

Published: 18 March 2011

\section{References}

1. Sensebé $L$, Bourin $P$, Tarte K: Good manufacturing practices production of mesenchymal stem/stromal cells. Hum Gene Ther 2010, 22:19-26.

2. Friedenstein AJ, Gorskaja JF, Kulagina NN: Fibroblast precursors in normal and irradiated mouse hematopoietic organs. Exp Hematol 1976, 4:267-274

3. Zuk PA, Zhu M, Ashjian P, De Ugarte DA, Huang Jl, Mizuno H, Alfonso ZC, Fraser JK, Benhaim $\mathrm{P}$, Hedrick MH: Human adipose tissue is a source of multipotent stem cells. Mol Biol Cell 2002, 13:4279-4295.

4. Fukuchi Y, Nakajima H, Sugiyama D, Hirose I, Kitamura T, Tsuji K: Human placenta-derived cells have mesenchymal stem/progenitor cell potential. Stem Cells 2004, 22:649-658.

5. Romanov YA, Svintsitskaya VA, Smirnov VN: Searching for alternative sources of postnatal human mesenchymal stem cells: candidate MSC-like cells from umbilical cord. Stem Cells 2003, 21:105-110.

6. Gronthos S, Mankani M, Brahim J, Robey PG, Shi S: Postnatal human dental pulp stem cells (DPSCs) in vitro and in vivo. Proc Natl Acad Sci U S A 2000, 97:13625-13630.

7. Bi Y, Ehirchiou D, Kilts TM, Inkson CA, Embree MC, Sonoyama W, Li L, Leet Al, Seo BM, Zhang L, Shi S, Young MF: Identification of tendon stem/progenitor cells and the role of the extracellular matrix in their niche. Nat Med 2007, 13:1219-1227.

8. Nöth U, Osyczka AM, Tuli R, Hickok NJ, Danielson KG, Tuan RS: Multilineage mesenchymal differentiation potential of human trabecular bone-derived cells. J Orthop Res 2002, 20:1060-1069.

9. De Bari C, Dell'Accio F, Tylzanowski P, Luyten FP: Multipotent mesenchymal stem cells from adult human synovial membrane. Arthritis Rheum 2001, 44:1928-1942.

10. da Silva Meirelles $L$, Chagastelles PC, Nardi NB: Mesenchymal stem cells reside in virtually all post-natal organs and tissues. J Cell Sci 2006, 119:2204-2213.

11. Noël D, Caton D, Roche S, Bony C, Lehmann S, Casteilla L, Jorgensen C, Cousin $B$ : Cell specific differences between human adipose-derived and mesenchymal-stromal cells despite similar differentiation potentials. Exp Cell Res 2008, 314:1575-1584.

12. Crisan M, Yap S, Casteilla L, Chen CW, Corselli M, Park TS, Andriolo G, Sun B, Zheng B, Zhang L, Norotte C, Teng PN, Traas J, Schugar R, Deasy BM, Badylak S, Buhring HJ, Giacobino JP, Lazzari L, Huard J, Péault B: A perivascular origin for mesenchymal stem cells in multiple human organs. Cell Stem Cell 2008 3:301-313.

13. da Silva Meirelles L, Caplan Al, Nardi NB: In search of the in vivo identity of mesenchymal stem cells. Stem Cells 2008, 26:2287-2299.

14. Maumus M, Peyrafitte JA, D'Angelo R, Fournier-Wirth C, Bouloumié A, Casteilla $L$, Sengenès $C$, Bourin P: Native human adipose stromal cells: localization, morphology and phenotype. Int J Obes (Lond) 2011 [Epub ahead of print]

15. Dominici M, Le Blanc K, Mueller I, Slaper-Cortenbach I, Marini F, Krause D, Deans R, Keating A, Prockop D, Horwitz E: Minimal criteria for defining multipotent mesenchymal stromal cells. The International Society for Cellular Therapy position statement. Cytotherapy 2006, 8:315-317.

16. Bühring HJ, Battula VL, Treml S, Schewe B, Kanz L, Vogel W: Novel markers for the prospective isolation of human MSC. Ann N Y Acad Sci 2007, 1106:262-271.

17. Sengenès C, Lolmède $K$, Zakaroff-Girard A, Busse R, Bouloumié A: Preadipocytes in the human subcutaneous adipose tissue display distinct features from the adult mesenchymal and hematopoietic stem cells. J Cell Physiol 2005, 205:114-122.

18. Pittenger MF, Mackay AM, Beck SC, Jaiswal RK, Douglas R, Mosca JD, Moorman MA, Simonetti DW, Craig S, Marshak DR: Multilineage potential of adult human mesenchymal stem cells. Science 1999, 284:143-147.

19. Wakitani S, Saito T, Caplan Al: Myogenic cells derived from rat bone marrow mesenchymal stem cells exposed to 5-azacytidine. Muscle Nerve 1995 18:1417-1426

20. Young RG, Butler DL, Weber W, Caplan Al, Gordon SL, Fink DJ: Use of mesenchymal stem cells in a collagen matrix for Achilles tendon repair. J Orthop Res 1998, 16:406-413.

21. Makino S, Fukuda K, Miyoshi S, Konishi F, Kodama H, Pan J, Sano M, Takahashi T, Hori S, Abe H, Hata J, Umezawa A, Ogawa S: Cardiomyocytes can be generated from marrow stromal cells in vitro. J Clin Invest 1999, 103:697-705.

22. Sanchez-Ramos J, Song S, Cardozo-Pelaez F, Hazzi C, Stedeford T, Willing A, Freeman TB, Saporta S, Janssen W, Patel N, Cooper DR, Sanberg PR: Adult bone marrow stromal cells differentiate into neural cells in vitro. Exp Neurol 
2000, 164:247-256.

23. Tropel P, Platet N, Platel JC, Noël D, Albrieux M, Benabid AL, Berger F: Functional neuronal differentiation of bone marrow-derived mesenchymal stem cells. Stem Cells 2006, 24:2868-2876.

24. Ghannam S, Bouffi C, Djouad F, Jorgensen C, Noël D: Immunosuppression by mesenchymal stem cells: mechanisms and clinical applications. Stem Cell Res Ther 2010, 1:2.

25. Krampera M, Cosmi L, Angeli R, Pasini A, Liotta F, Andreini A, Santarlasci V, Mazzinghi B, Pizzolo G, Vinante F, Romagnani P, Maggi E, Romagnani S, Annunziato F: Role for interferon-gamma in the immunomodulatory activity of human bone marrow mesenchymal stem cells. Stem Cells 2006 24:386-398.

26. Ren G, Zhang L, Zhao X, Xu G, Zhang Y, Roberts Al, Zhao RC, Shi Y Mesenchymal stem cell-mediated immunosuppression occurs via concerted action of chemokines and nitric oxide. Cell Stem Cell 2008, 2:141-150.

27. Djouad F, Charbonnier LM, Bouffi C, Louis-Plence P, Bony C, Apparailly F, Cantos C, Jorgensen C, Noël D: Mesenchymal stem cells inhibit the differentiation of dendritic cells through an interleukin-6-dependent mechanism. Stem Cells 2007, 25:2025-2032.

28. Nauta AJ, Kruisselbrink AB, Lurvink E, Willemze R, Fibbe WE: Mesenchyma stem cells inhibit generation and function of both CD34+-derived and monocyte-derived dendritic cells. J Immuno/ 2006, 177:2080-2087.

29. Ghannam S, Pène J, Torcy-Moquet G, Jorgensen C, Yssel H: Mesenchymal stem cells inhibit human Th17 cell differentiation and function and induce a T regulatory cell phenotype. J Immunol 2010, 185:302-312.

30. Waterman RS, Tomchuck SL, Henkle SL, Betancourt AM: A new mesenchymal stem cell (MSC) paradigm: polarization into a pro-inflammatory MSC1 or an Immunosuppressive MSC2 phenotype. PLoS One 2010, 5:e10088.

31. Shabbir A, Zisa D, Suzuki G, Lee T: Heart failure therapy mediated by the trophic activities of bone marrow mesenchymal stem cells: a noninvasive therapeutic regimen. Am J Physiol Heart Circ Physio/ 2009, 296:H1888-1897.

32. Shabbir A, Zisa D, Lin H, Mastri M, Roloff G, Suzuki G, Lee T: Activation of host tissue trophic factors through JAK-STAT3 signaling: a mechanism of mesenchymal stem cell-mediated cardiac repair. Am J Physiol Heart Circ Physiol 2010, 299:H1428-1438.

33. Wang Y, Abarbanell AM, Herrmann JL, Weil BR, Manukyan MC, Poynter JA, Meldrum DR: TLR4 inhibits mesenchymal stem cell (MSC) STAT3 activation and thereby exerts deleterious effects on MSC-mediated cardioprotection. PLoS One 2010, 5:e14206.

34. Tögel F, Cohen A, Zhang P, Yang Y, Hu Z, Westenfelder C: Autologous and allogeneic marrow stromal cells are safe and effective for the treatment of acute kidney injury. Stem Cells Dev 2009, 18:475-485.

35. Semedo P, Correa-Costa M, Antonio Cenedeze M, Maria Avancini Costa Malheiros D, Antonia dos Reis M, Shimizu MH, Seguro AC, Pacheco-Silva A Saraiva Camara NO: Mesenchymal stem cells attenuate renal fibrosis through immune modulation and remodeling properties in a rat remnant kidney model. Stem Cells 2009, 27:3063-3073.

36. Lozito TP, Tuan RS: Mesenchymal stem cells inhibit both endogenous and exogenous MMPs via secreted TIMPs. J Cell Physiol 2011, 226:385-396.

37. Dixon JA, Gorman RC, Stroud RE, Bouges S, Hirotsugu H, Gorman JH, Martens TP, Itescu S, Schuster MD, Plappert T, St John-Sutton MG, Spinale FG Mesenchymal cell transplantation and myocardial remodeling after myocardial infarction. Circulation 2009, 120:S220-229.

38. Fong EL, Chan CK, Goodman SB: Stem cell homing in musculoskeletal injury. Biomaterials 2011, 32:395-409.

39. Drosse I, Volkmer E, Capanna R, De Biase P, Mutschler W, Schieker M: Tissue engineering for bone defect healing: an update on a multi-component approach. Injury 2008, 39 Suppl 2:S9-20.

40. Will J, Melcher R, Treul C, Travitzky N, Kneser U, Polykandriotis E, Horch R, Greil $\mathrm{P}$ : Porous ceramic bone scaffolds for vascularized bone tissue regeneration. J Mater Sci Mater Med 2008, 19:2781-2790.

41. Vinatier C, Mrugala D, Jorgensen C, Guicheux J, Noël D: Cartilage engineering: a crucial combination of cells, biomaterials and biofactors. Trends Biotechnol 2009, 27:307-314

42. Shanmugasundaram S, Chaudhry H, Arinzeh TL: Microscale versus nanoscale scaffold architecture for mesenchymal stem cell chondrogenesis. Tissue Eng Part A 2010, 17:831-840.
43. Wang W, Li B, Yang J, Xin L, Li Y, Yin H, Qi Y, Jiang Y, Ouyang H, Gao C: The restoration of full-thickness cartilage defects with BMSCs and TGF-beta 1 loaded PLGA/fibrin gel constructs. Biomaterials 2010, 31:8964-8973.

44. Bouffi C, Thomas O, Bony C, Giteau A, Venier-Julienne MC, Jorgensen C, Montero-Menei C, Noël D: The role of pharmacologically active microcarriers releasing TGF-beta3 in cartilage formation in vivo by mesenchymal stem cells. Biomaterials 2010, 31:6485-6493.

45. Lee CH, Cook JL, Mendelson A, Moioli EK, Yao H, Mao JJ: Regeneration of the articular surface of the rabbit synovial joint by cell homing: a proof of concept study. Lancet 2010, 376:440-448.

46. Undale AH, Westendorf JJ, Yaszemski MJ, Khosla S: Mesenchymal stem cells for bone repair and metabolic bone diseases. Mayo Clin Proc 2009, 84:893-902.

47. Horwitz EM, Prockop DJ, Fitzpatrick LA, Koo WW, Gordon PL, Neel M, Sussman M, Orchard P, Marx JC, Pyeritz RE, Brenner MK: Transplantability and therapeutic effects of bone marrow-derived mesenchymal cells in children with osteogenesis imperfecta. Nat Med 1999, 5:309-313.

48. Horwitz EM, Gordon PL, Koo WK, Marx JC, Neel MD, McNall RY, Muul L, Hofmann T: Isolated allogeneic bone marrow-derived mesenchymal cells engraft and stimulate growth in children with osteogenesis imperfecta: Implications for cell therapy of bone. Proc Natl Acad Sci U SA 2002, 99:8932-8937.

49. Le Blanc K, Götherström C, Ringdén O, Hassan M, McMahon R, Horwitz E, Anneren G, Axelsson O, Nunn J, Ewald U, Nordén-Lindeberg S, Jansson M, Dalton A, Aström E, Westgren M: Fetal mesenchymal stem-cell engraftment in bone after in utero transplantation in a patient with severe osteogenesis imperfecta. Transplantation 2005, 79:1607-1614.

50. Whyte MP, Kurtzberg J, McAlister WH, Mumm S, Podgornik MN, Coburn SP Ryan LM, Miller CR, Gottesman GS, Smith AK, Douville J, Waters-Pick B, Armstrong RD, Martin PL: Marrow cell transplantation for infantile hypophosphatasia. J Bone Miner Res 2003, 18:624-636.

51. Augello A, Tasso R, Negrini SM, Cancedda R, Pennesi G: Cell therapy using allogeneic bone marrow mesenchymal stem cells prevents tissue damage in collagen-induced arthritis. Arthritis Rheum 2007, 56:1175-1186.

52. González MA, Gonzalez-Rey E, Rico L, Büscher D, Delgado M: Treatment of experimental arthritis by inducing immune tolerance with human adipose-derived mesenchymal stem cells. Arthritis Rheum 2009, 60:1006-1019.

53. Bouffi C, Bony C, Courties G, Jorgensen C, Noël D: IL-6-dependent PGE2 secretion by mesenchymal stem cells inhibits local inflammation in experimental arthritis. PLoS One 2010, 5:e14247.

54. Djouad F, Fritz V, Apparailly F, Louis-Plence P, Bony C, Sany J, Jorgensen C, Noël $D$ : Reversal of the immunosuppressive properties of mesenchymal stem cells by tumor necrosis factor alpha in collagen-induced arthritis. Arthritis Rheum 2005, 52:1595-1603.

55. Schurgers E, Kelchtermans H, Mitera T, Geboes L, Matthys P: Discrepancy between the in vitro and in vivo effects of murine mesenchymal stem cells on T-cell proliferation and collagen-induced arthritis. Arthritis Res Ther 2010, 12:R31.

56. Nöth U, Steinert AF, Tuan RS: Technology insight: adult mesenchymal stem cells for osteoarthritis therapy. Nat Clin Pract Rheumatol 2008, 4:371-380.

57. Aung A, Gupta G, Majid G, Varghese S: Osteoarthritic chondrocyte-secreted morphogens induce chondrogenic differentiation of human mesenschymal stem cells. Arthritis Rheum 2010, 63:148-158.

58. Murphy JM, Fink DJ, Hunziker EB, Barry FP: Stem cell therapy in a caprine model of osteoarthritis. Arthritis Rheum 2003, 48:3464-3474.

59. Grigolo B, Lisignoli G, Desando G, Cavallo C, Marconi E, Tschon M, Giavaresi G, Fini M, Giardino R, Facchini A: Osteoarthritis treated with mesenchymal stem cells on hyaluronan-based scaffold in rabbit. Tissue Eng Part C Methods 2009, 15:647-658.

doi:10.1186/scrt55

Cite this article as: Maumus $M$, et al.: Mesenchymal stem cell-based

therapies in regenerative medicine: applications in rheumatology. Stem Cell Research \& Therapy 2011, 2:14. 